\title{
Analysis of community attributes of the benthic meiofauna of Frierfjord/Langesundfjord
}

\author{
C. Heip ${ }^{1}{ }^{*}$, R. M. Warwick ${ }^{2}$, M. R. Carr $^{2}$, P. M. J. Herman ${ }^{1}$, R. Huys ${ }^{1}$, N. Smol ${ }^{1}$, \\ K. Van Holsbeke ${ }^{1}$
}

${ }^{1}$ Marine Biology Section, Institute of Zoology, State University of Gent, K. L. Ledeganckstraat 35, B-9000 Gent, Belgium ${ }^{2}$ Plymouth Marine Laboratory (West Hoe), Prospect Place, The Hoe, Plymouth PL1 3DH, United Kingdom

\begin{abstract}
Sublittoral meiofauna was sampled for the GEEP Workshop along a putative pollution gradient at 6 sites in Frierfjord/Langesundfjord, Norway. Data were subjected to mutivariate statistical analyses which discriminate between sites on their faunistic attributes, and univariate measures of community stress were determined. Most multivariate techniques produced similar results. The copepod component of the meiofauna discriminated between sites better than the nematodes at the species level, but nematodes were more robust to analyses based on data aggregated to higher taxonomic levels. It is concluded that pollution monitoring at the community level using higher taxonomic groupings of meiofauna is viable, and renders such studies much less time-consuming and more cost-effective than more standard procedures. Appropriate taxonomic levels for the 2 major meiofaunal taxa (nematodes and copepods) and for the total meiofauna are discussed. There is a paucity of validated univariate measures of community perturbation available for use with meiofauna. Traditional diversity measures were rather uninformative, but the community at one site was identified as being adversely affected by pollution.
\end{abstract}

\section{INTRODUCTION}

Meiofauna are small metazoan organisms which have a distinct biological and operational identity. They are isolated as a peak in the benthic biomass sizespectrum, separated from the larger macrofauna and smaller microbes (Schwinghamer 1981). Soft sediments accommodate a relatively large number of meiofaunal and macrofaunal sized species, but very few of intermediate size (Warwick 1984), this latter pattern probably arising from the evolutionary optimization of very different size related life-history and feeding characteristics in the two groups of animals. Meiofauna are in the 100 to $10000 \mathrm{um}$ size range, and have been methodologically defined as passing through a 0.5 or $1 \mathrm{~mm}$ mesh sieve, but retained on a $63 \mu \mathrm{m}$ mesh (the silt/sand boundary sieve).

Responses of meiofaunal communities to perturbation, including pollution, have been less well studied than those of the macrofauna. Because of their different

\footnotetext{
- Present address: Delta Institute for Hydrobiological Research, Vierstraat 28, 4401EA Yerseke, The Netherlands
}

biological characteristics, it cannot be assumed that meiofaunal responses will be qualitatively the same as those of the macrofauna, and some important differences have already been noted. For example, there is a shift towards smaller sized species of macrofauna under polluted conditions and a shift towards larger sized species of meiofauna (Warwick et al. 1986) Mechanisms of diversity maintenance also differ in the 2 size categories. Meiofaunal diversity, which is maintained largely by a high degree of feeding specialization on particles of different size, shape and quality, is likely to be less affected by physical perturbations than that of macrofauna, in which spatial segregation of species is a more important element in diversity maintenance (Warwick 1984).

Whilst less is currently known about meiofaunal responses to pollutants, they have certain inherent advantages over the macrofauna in the determination of the biological effects of pollutants at the community level. Since much smaller sediment samples are required they do not require preliminary processing (i.e. sieving) in the field. Sampling is thus much less labour-intensive and generally, for sublittoral work, requires the use of small research vessels or launches 
which would be unsuitable for macrofauna sampling and processing. Arguably, meiofaunal communities are inherently more stable, both qualitatively and quantitatively, on a seasonal and year-to-year basis, than those of the macrofauna (Heip 1980, Warwick 1980, Heip \& Herman 1985, Herman \& Heip 1986), and it is obviously easier to monitor temporal changes in community structure from a stable rather than a fluctuating baseline. The shorter generation times of meiofauna result in a faster potential response time to pollution incidents, changes in community structure taking place over a timespan of months rather than years, which may be an advantage in certain situations. The meiofauna are abundant and diverse even in habitats, such as estuaries, which are subjected to considerable natural physical and chemical stress and where only a handful of macrofauna species remains, occasionally none at all. It is thus much easier to perceive, and monitor changes in, community structure of the meiofauna in such situations.

The overriding drawback to the use of meiofauna in pollution studies is that they have been traditionally regarded as difficult taxonomically. An adequate taxonomic literature to enable identification of the major groups of meiofaunal organisms to species level is lacking for all regions of the world, although the situation is beginning to improve in Northern Europe and North America. Sorting and species determination can only be done realistically by a group of specialists in the various major taxa (as was the case with this paper). Also, logistics of biological surveys generally demand that the animals be directly fixed and preserved (usually with formalin) in the sediment, prior to extraction and sorting in the laboratory. Certain so called 'soft' meiofaunal taxa such as turbellarians and gastrotrichs are rendered virtually unrecognizable by this treatment and really require to be extracted from the sediment and examined alive, or at least require special methods of fixation and processing which are peculiar to individual groups. In practice this latter problem is not particularly acute, since two of the 'hard' taxa, the nematodes and copepods, overwhelmingly predominate in most soft-sediment samples (McIntyre 1969).

In view of the taxonomic problems, there has been a general move towards trying to develop methodologies for using meiofauna in pollution-studies at taxonomic levels higher than that of species. However, these have tended to be simplistic and sometimes confusing, e.g. the now controversial nematode:copepod ratio (Raffaelli \& Mason 1981). In this paper, we have therefore tried to follow through the sequence of multivariate and univariate procedures employed by Gray et al. (1988) for the macrofauna of Langesund and Frierfjord, to see how robust they are to hierarchical changes in the taxonomic grouping of meiofauna.

\section{MATERIAL AND METHODS}

Details of the sampling methods are given in Follum \& Moe (1988). In summary, 5 replicate $24.6 \mathrm{~cm}^{2}$ Craib core samples of sediment to a depth of $8 \mathrm{~cm}$ were taken from 6 sites: A (depth $75 \mathrm{~m}), \mathrm{B}(113 \mathrm{~m}), \mathrm{C}(107 \mathrm{~m}), \mathrm{D}$ $(99 \mathrm{~m}), \mathrm{E}(22 \mathrm{~m})$ and $\mathrm{F}(86 \mathrm{~m})$; see Follum \& Moe (1988) for locations (their Fig. 2) and sediment granulometry at these sites (their Table 5). At Sites A, B, C and E the sediments were visually similar in the cores, with a distinct boundary between the surface light-coloured 'aerobic' layer and a deeper darker 'anaerobic' layer. Some cores penetrated a deeper 'shell-grit' layer. Site F comprised fluid black mud smelling strongly of sulphide, with large flakes producing a 'snowstorm' effect when disturbed, underlain by a shell-grit layer. At Site $D$ the sediment had a flocculent surface layer down to 4 to $5 \mathrm{~cm}$, and was light coloured and 'aerobic' to a depth of nearly $8 \mathrm{~cm}$, containing many protruding polychaete tubes. Pollution levels at these sites are presented in Appendix 1 for hydrocarbons (Table 2 and Fig. 1) and for metals (Table 12 and Fig. 3). Site A had the lowest metal levels, but did not have lower PAHs. Site $F$ had clearly higher values for $\mathrm{Cd}$ and PAHs, though not for other heavy metals. There were no obvious differences in loadings between Sites B, C and D (Fig. 14 of Gray et al. 1988) but Site E was distinguishable from these by its slightly lower levels of some metals (e.g. Fe, Mn, Ni).

Meiofauna were extracted from 4 replicates at each site using the LUDOX centrifugation flotation technique described by McIntyre \& Warwick (1984) and Heip et al. (1985). In all 4 replicates meiofauna were enumerated to major taxon level. For this study, we have taken an operational definition of meiofauna, i.e. all metazoan organisms retained on the $63 \mu \mathrm{m}$ sieve, so that some of the categories (e.g. polychaetes) will include larvae of macrofaunal species. This was considered appropriate as a test of the method, since similar studies by less experienced taxonomists might fail to distinguish larval macrofauna from true meiofauna. There were 19 taxa: Acari, Amphipoda, Bivalvia, Copepoda, Cumacea, Echinodermata, Gastrotricha, Hydrozod, Isopoda, Kinorhyncha, Nauplii (of all crustacean groups), Nematoda, Oligochaeta, Ostracoda, Polychaeta, Priapulida, Tanaidacea, Tardigrada and Turbellaria. For the 2 most abundant taxa, the first 200 nematodes from 2 cores and all copepods from 3 cores were identified to species level. For data analysis, these 2 taxa were subjected to several levels of taxonomic aggregation: nematodes to genera, families, sub-orders and orders, and copepods to genus and family Nematodes were also aggregated on a non-taxonomic functional basis: the feeding category as deduced from the structure of the buccal cavity. Whilst there have 
been several alterations and refinements to Wieser's (1953) classification of nematode feeding types, these often require a degree of taxonomic sophistication beyond simple observation of structure in order to allocate specimens to a category. We have therefore adhered to Wieser's original groupings, since they can be identified by workers with no taxonomic training. They are:

(1A) no buccal cavity or a fine tubular one - selective deposit (bacterial) feeders;

(1B) large but unarmed buccal cavity - non-selective deposit feeders;

(2A) buccal cavity with scraping tooth or teeth epistrate (diatom) feeders;

(2B) buccal cavity with large jaws - predators/omnivores.

Dry weights of copepods and nematodes were determined using a Mettler microbalance after drying in a dessicator for $2 \mathrm{~h}$.

\section{DATA ANALYSIS}

Multivariate methods. The suite of multivariate statistical techniques applied to the GEEP Workshop data is described by Gray et al. (1988), and the rationale behind many of them by Clarke \& Green (1988). Those techniques applied to the meiofauna data were: classification - clustering based on the BrayCurtis similarity index and group average sorting of 4 th root transformed abundance data, and 2-way indicator species analysis (TWINSPAN); ordination - MDS and DECORANA.

Univariate methods. Abundance, biomass and diversity were analysed using classical 1-way ANOVA. If significant differences between sites were found, they were checked with 'a posteriori' comparisons, using a pooled mean square within sites (Sokal \& Rohlf 1981).

Diversity was calculated as Hill's diversity numbers (Hill 1973), based on the general entropy measure proposed by Renyi (1961). This incorporates the most widely used diversity measures in a coherent system in which the impact of the dominance-related aspect of diversity increases with increasing orders, the impact of species-richness decreasing. Of particular interest are the diversity numbers of Order $0,1,2$ and $\infty$, viz.

$$
\begin{gathered}
N_{0}=S \\
N_{1}=\exp (H) \text {, where } H=-\Sigma p_{i} \ln \left(p_{1}\right), \\
N_{2}=S I^{-1}, \text { where } S I=\Sigma p_{i}^{2}, \\
N_{\infty}=p_{1}^{-1},
\end{gathered}
$$

and $p_{i}(i=1,2, \ldots, S)=$ the relative abundance of the $i$ th most dominant species ( $H=$ the Shannon-Wiener diversity, $S I=$ Simpon's dominance index).
Evenness in Hill's system is calculated as $N_{1} / N_{0}$ (= $\left.N_{10}\right)$ or $N_{2} / N_{1}\left(=N_{21}\right)$, or modifications thereof:

$$
\begin{gathered}
N_{10^{\prime}}=\left(N_{1}-1\right) /\left(N_{0}-1\right) \quad(\text { Heip 1974), } \\
N_{21}^{\prime}=\left(N_{2}-1\right) /\left(N_{1}-1\right) \quad \text { (Alatalo 1981). }
\end{gathered}
$$

\section{RESULTS}

Raw data are tabulated in Appendix 3, Tables 5 to 7.

\section{Discrimination between sites: multivariate analyses}

\section{Nematoda}

A total of 167 species or putative species was found during the survey, many of which could not be attributed to previously described species. Cluster analyses
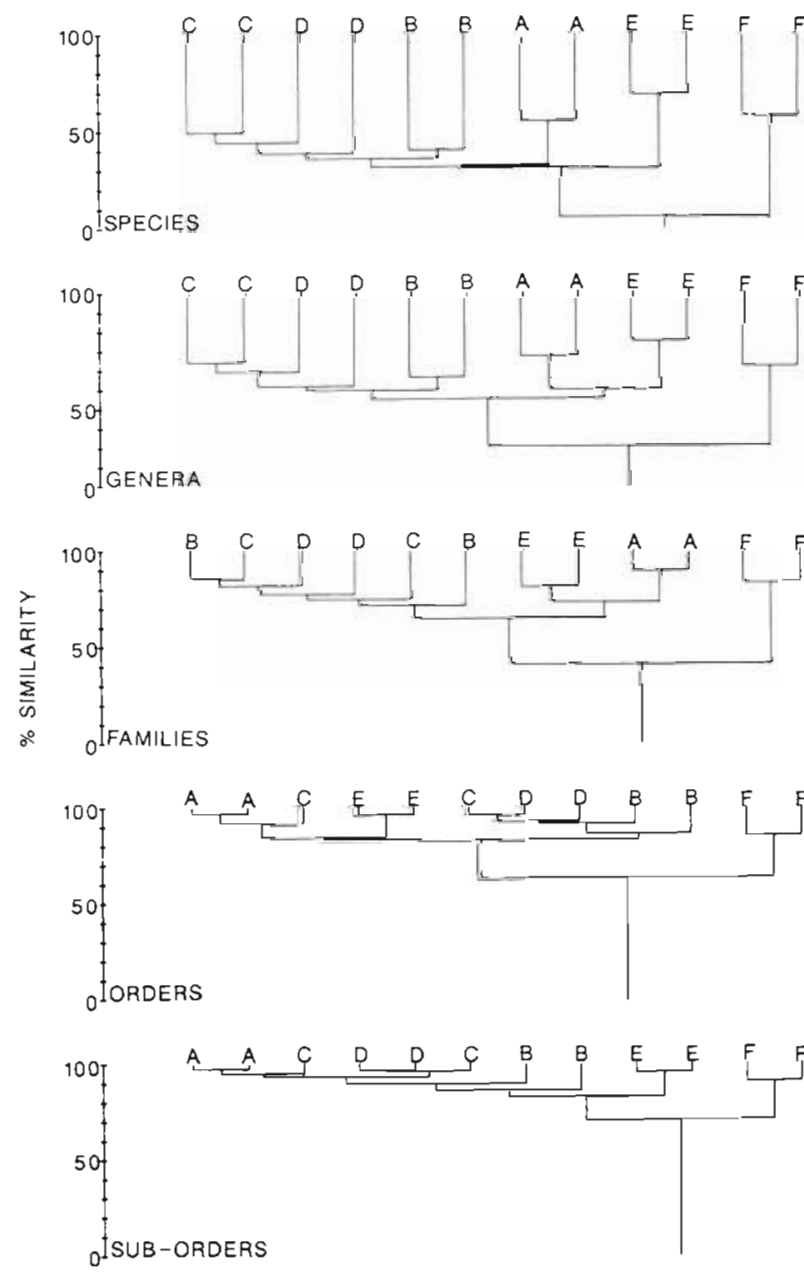

Fig. 1. Nematodes. Dendrograms for group average clustering of Bray-Curtis similarities, based on 4 th root transformed abundance data for $n=2$ replicates at each of Sites $A$ to $F$, applying 5 levels of taxonomic aggregation from species to orders 
(Fig. 1) showed that, at all levels of taxonomic aggregation, the replicates of Site F were faunistically very different from the others. Replicates of Sites A and E consistently clustered together; these two sites were most similar to each other at the family level and below, but intermingled with $B, C$ and $D$ replicates at the level of sub-orders and orders. Within this latter cluster, B and $C$ replicates remain distinct up to the genus level only, above which $\mathrm{B}, \mathrm{C}$ and $\mathrm{D}$ replicates are intermingled. Dendrograms for species, genera and families have essentially similar configurations, and appreciable loss of information only occurs at the level of suborders and orders.

Ordinations are in general agreement with the cluster analyses. With MDS (4th root transformed abundance data), F replicates are so different from the others that the latter produce a tight cluster (Fig. 2). This is also apparent for an analysis based only on the 4 feeding-types (Fig. 3). These analyses have therefore
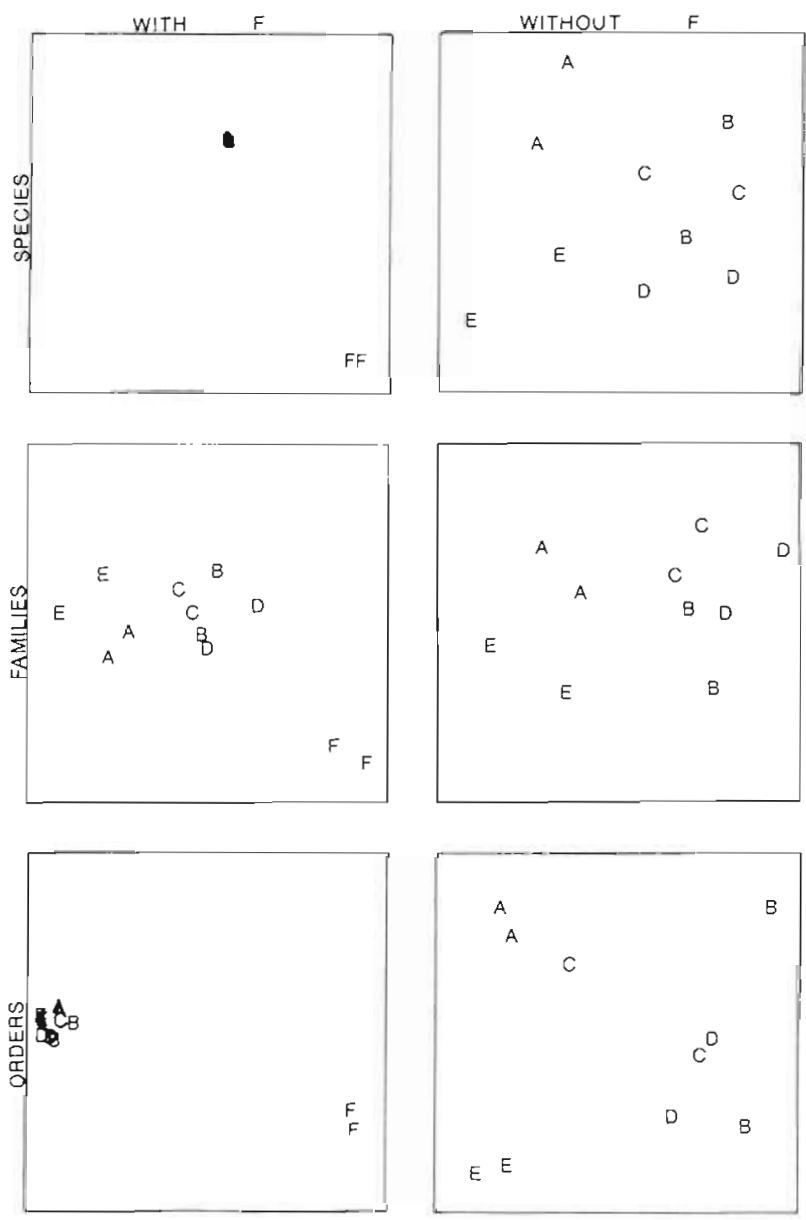

Fig. 2. Nematodes. Multidimensional scaling (MDS) plot in 2 dimensions of Bray-Curtis similarities, based on 4 th root transformed abundance data for Sites A to F (left) and omitting F (right), applying 3 levels of aggregation from species to orders. Stress coefficients (reading down columns) were 0.01 , $0.06,0.01,0.15,0.09$ and 0.04 been repeated omitting Site F. The replicates of Sites A and $E$ remain distinct at all levels of taxonomic agglomeration (Fig. 2) and also for the feeding-groups (Fig. 3), but they are more distinct for orders than for families or species. Even at the species level, replicates are not
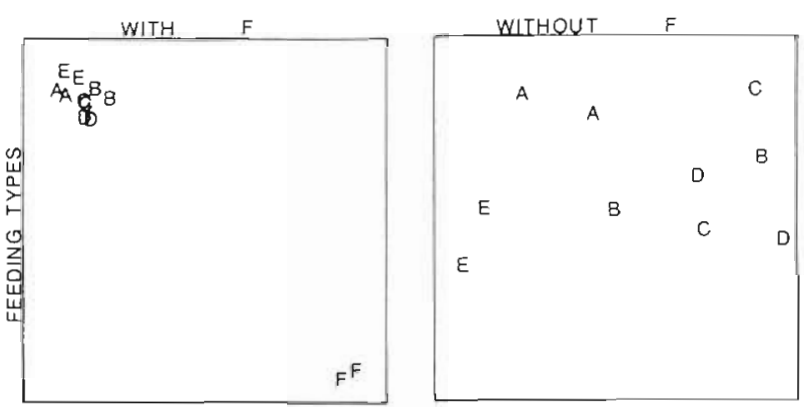

Fig. 3. Nematodes. As Fig. 2, but nematodes aggregated (ataxonomically) into their 4 feeding types. Stress $=0.01$ and 0.07
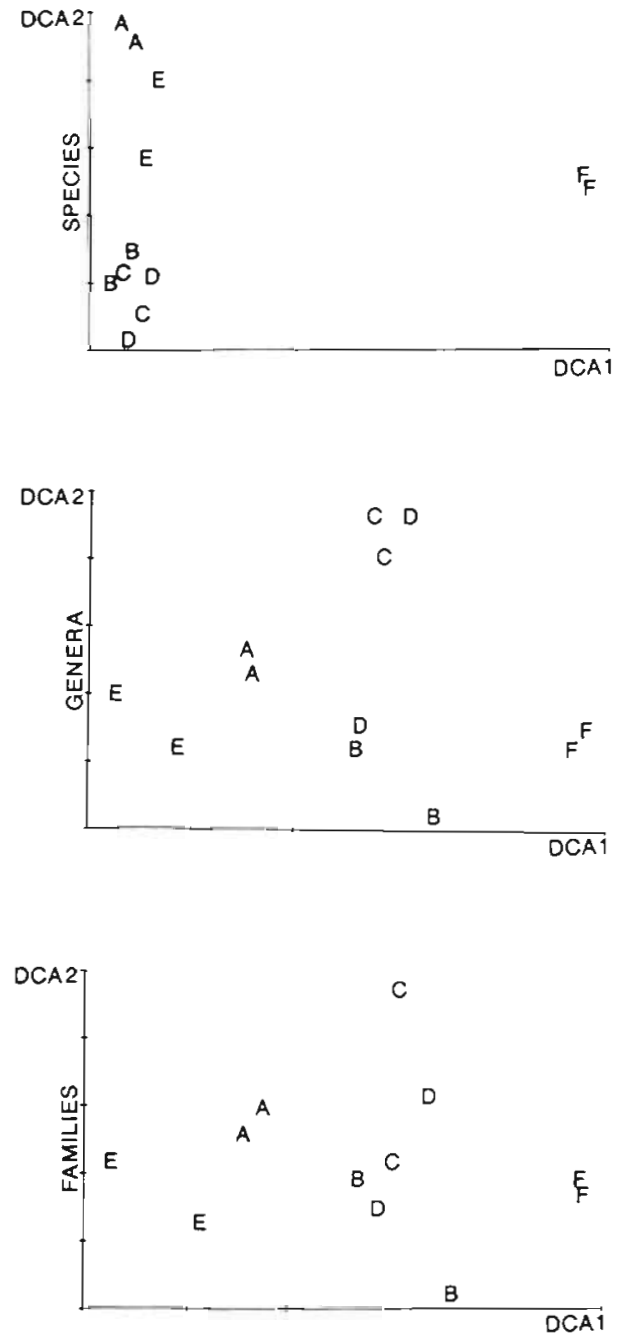

Fig. 4. Nematodes. Two-dimensional configuration from a detrended correspondence analysis (DECORANA) for Sites A to $F(n=2)$, applying 3 levels of aggregation 
separated within the $B, C$ and D cluster. DECORANA gives similar results (Fig. 4). At the species, genus and family levels, Sites A, E and F are separated with B. C and D completely intermingled. TWINSPAN also gave similar results, except that at the genus level there was no separation between $A$ and $E$, but at the family level this separation became clear again.
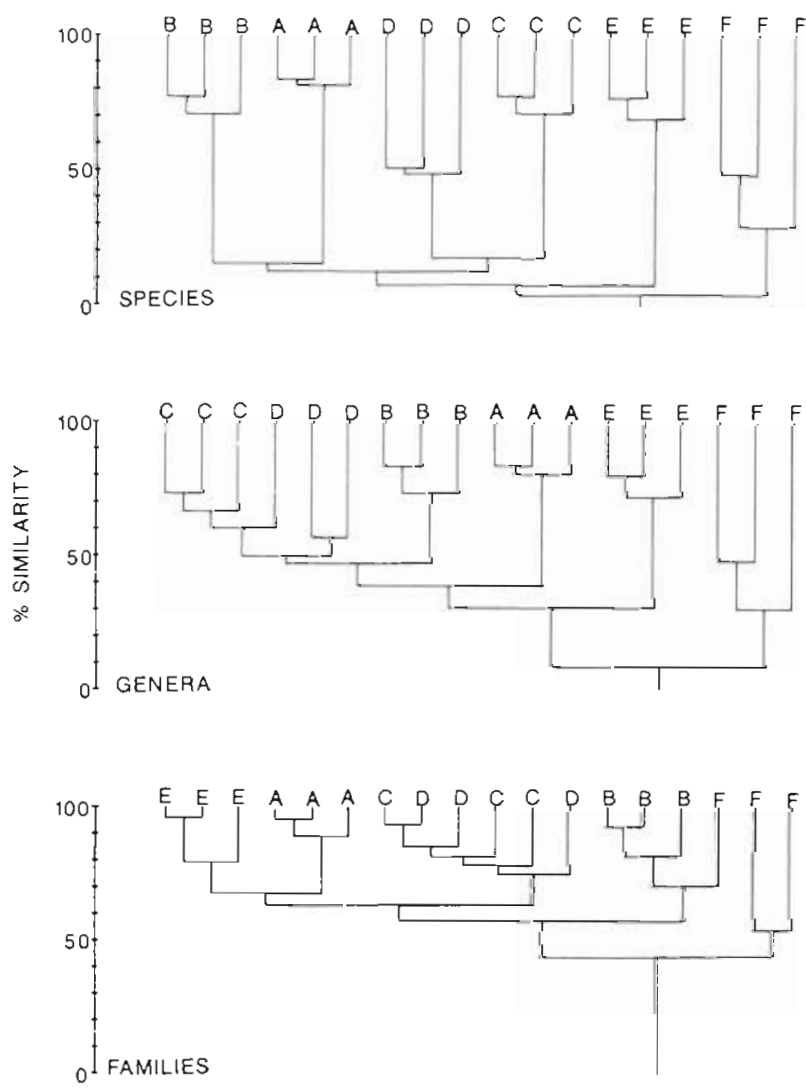

Fig. 5. Copepods. Dendrograms computed as for Fig. $1(n=3)$, for 3 levels of aggregation

\section{Copepoda}

A total of 106 species of copepods was found during the survey, belonging to 53 genera and 12 families. Clustering of replicates (Fig. 5) is perfect for species and near-perfect for genera with only one of the $D$ replicates showing greater similarity to the $\mathrm{C}$ cluster than to its fellows. At the family level, $C$ and D replicates become even more intermingled, and only 2 of the $3 \mathrm{~F}$ replicates are clearly separated.

The outcome of MDS ordinations at the species level was independent of the strength of transformation used, with the replicates at all sites clearly separated: some examples are given in Fig. 6. For genera and families (4th root transformed data), B, C and D become increasingly intermingled, $A$ and $E$ are less distinguishable for families and F replicates become increasingly scattered (Fig. 7). DECORANA gives similar results to MDS at the

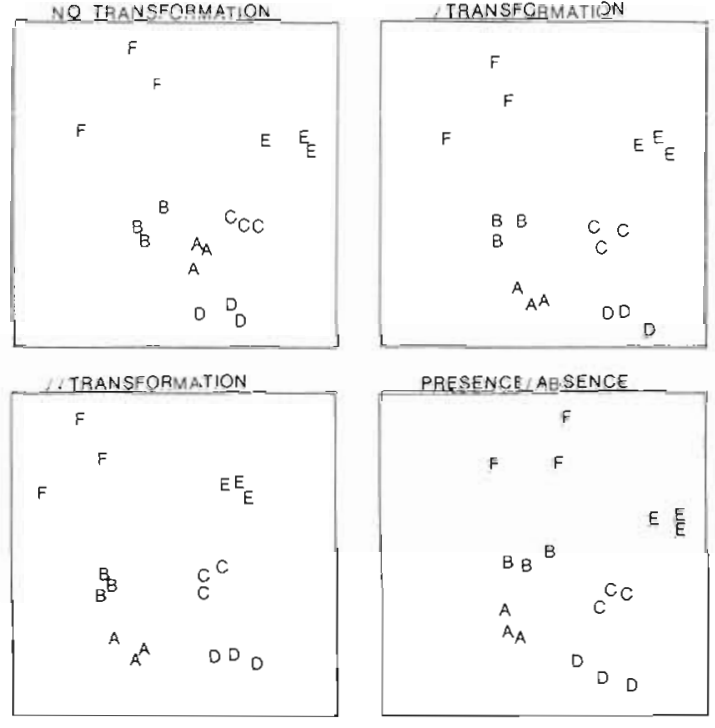

Fig. 6. Copepods. MDS plot of species at Sites A to $F(n=3)$, using Bray-Curtis similarity coefficients computed with different transformations: none, square root, 4 th root and presence/ absence. Stress coefficients increased from 0.12 to 0.14 respectively

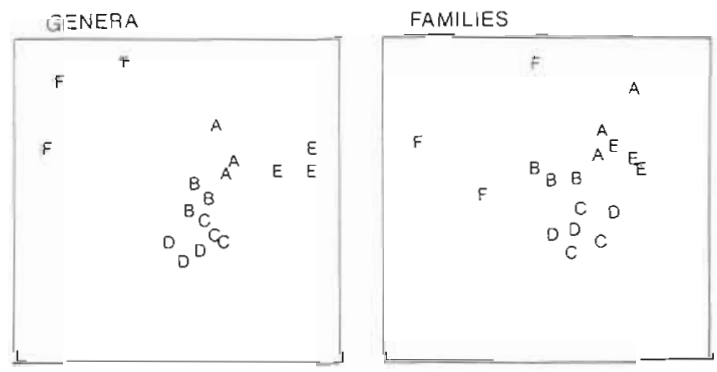

Fig. 7 Copepods. MDS plot from 4 th root transformed abundance data, after taxonomic aggregation to genera and families. Stress $=0.10$ in both cases. (See Fig. 6 for corresponding species analysis)

species level, with good separation of replicates except for $F$, which are widely scattered. This is largely due to the very low density of copepods at this site. The results of aggregation to genus and family levels were similar to those of MDS, but F replicates were always more widely scattered (Fig. 8). TWINSPAN again produced separation of replicates for species at all sites except $F$. There was also good separation for genera, with F, E and A clearly segregated whilst $D$ was split amongst $B$ and $C$. $A$ and $E$ were still separated at the family level, but $F$ was scattered.

\section{Meiofauna groups}

Classification based on the abundances of the 19 meiofaunal higher taxa resulted in only Sites $\mathrm{A}$ and $\mathrm{F}$ being distinct, in that their replicates clustered together (Fig. 9). The result was the same when the dominant 

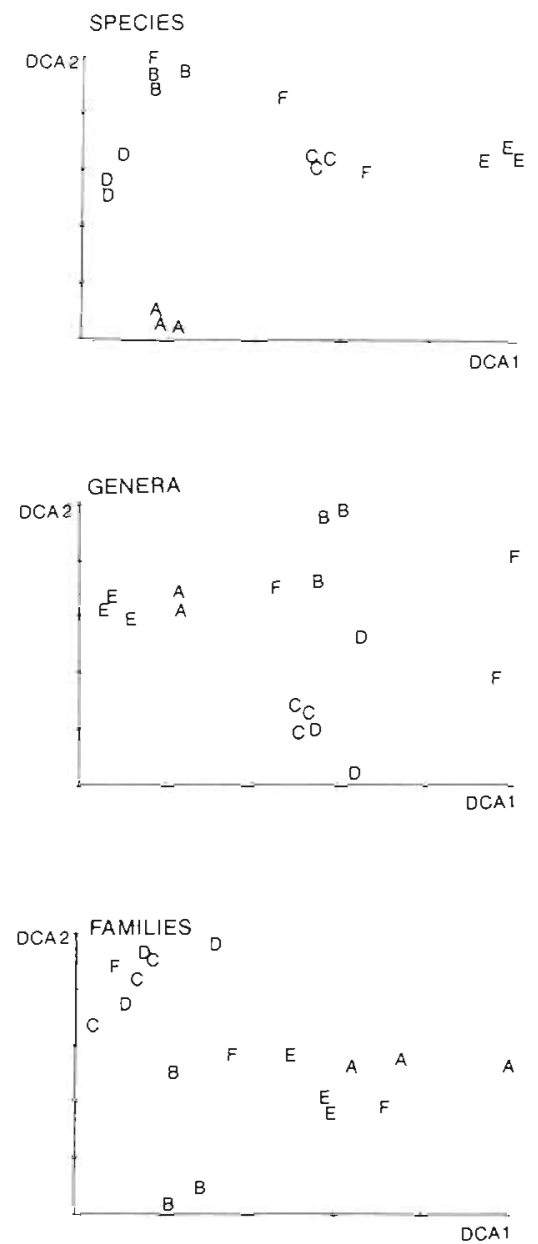

Fig. 8. Copepods. DECORANA plot for Sites A to $F(n=3)$, for 3 levels of aggregation

taxon, the Nematoda, was excluded from the analysis.

Ordinations gave marginally better separations. MDS (4th root transformation) separated $A, E$ and $F$ as distinct clusters, again regardless of whether or not the nematodes were included, but the $B, C$ and $D$ replicates were intermingled (Fig. 10). DECORANA (Fig. 11) and TWINSPAN gave similar results to MDS.

\section{Univariate indices}

\section{Nematoda}

Examples of the variations in diversity $\left(N_{0}, N_{1}\right.$ and $N_{2}$ ) between sites at the species level are given in Fig. 12. Similar patterns were apparent at the family, suborder and order level, and in nearly all instances there were significant differences in diversity between sites, the exceptions being $N_{0}$ at the sub-order level and $N_{2}$ at the family level. Site $F$ had a clearly lower diversity for all measures, although the difference between $F$

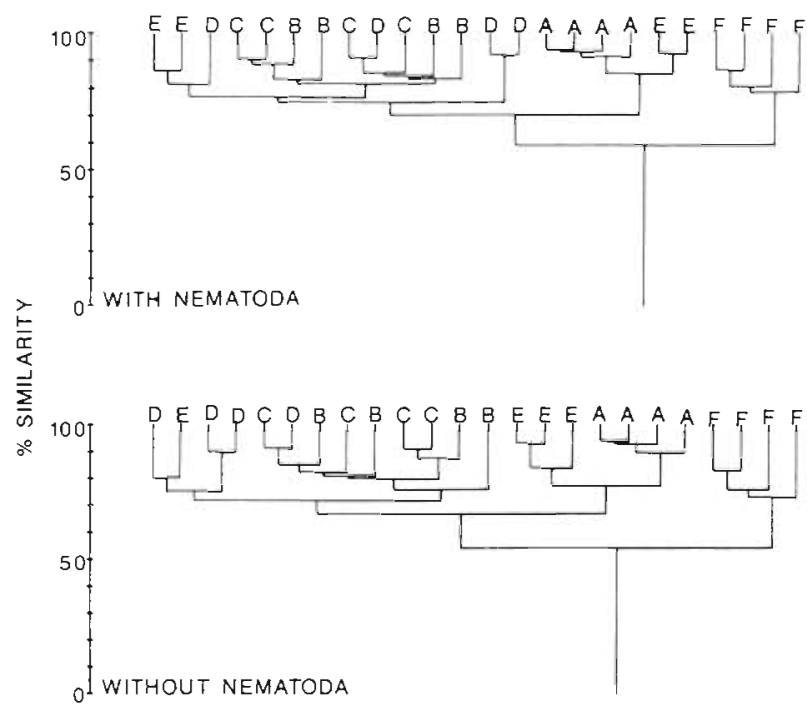

Fig. 9. Meiofauna major groups. Dendrograms computed as for Fig. $1(n=4)$. Upper dendrogram is for all 19 groups; lower omits the dominant nematodes
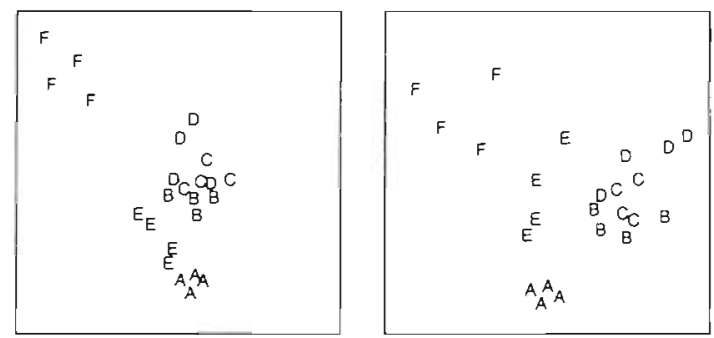

Fig. 10. Meiofauna major groups. MDS plot computed as for Fig. $2(n=4)$. Left, all 19 groups; right, the dominant nematodes omitted. Stress $=0.08,0.12$ respectively

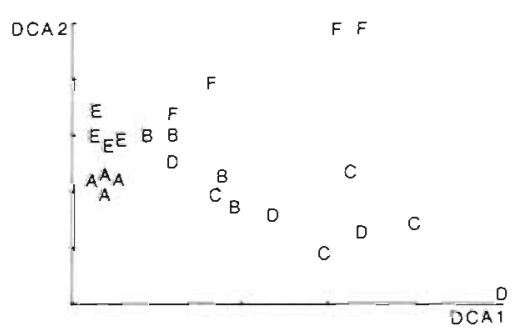

Fig. 11. Meiofauna major groups. DECORANA plot for Sites A to $F(n=4)$

and the other sites was not always significant. The level of aggregation applied influenced the relative diversities considerably. For example, Site A had the highest diversity at the species level and Site $D$ at the order level. When the data for the 2 replicates were combined and a $k$-dominance curve (Lambshead et al 1983) constructed for each site, F was clearly least diverse, followed in increasing order by $E$ and $B$, Sites $A, C$ and $D$ being indistinguishable from each other (crossing) and with the highest diversity (Fig. 13). 

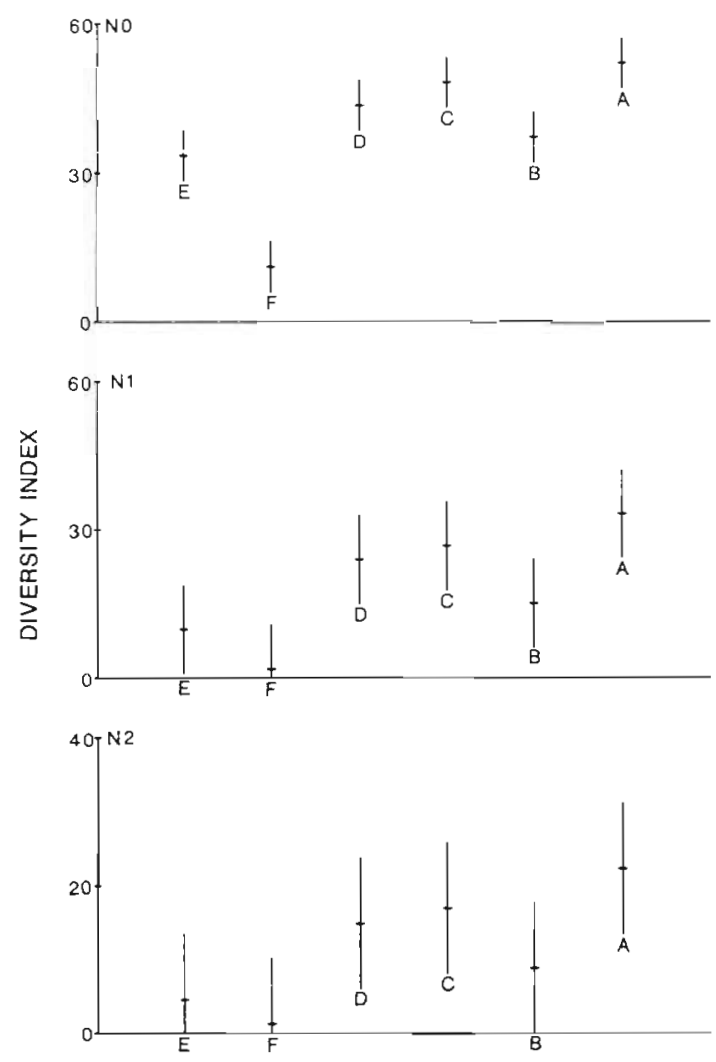

Fig. 12. Nematode species. Hill's diversity numbers $N_{0}, N_{1}$ and $N_{2}$ for Sites A to $\mathrm{F}(n=2)$. Means and 'comparison intervals' (non-overlapping intervals imply significant differences in a multiple comparison test)

\section{Copepoda}

Copepod diversity indices followed an essentially similar pattern to those of the nematodes (Fig. 14). Diversity was significantly lower at Site F, while A, B, C and $D$ were similar at all taxonomic levels. Site $E$ had an intermediate diversity in most analyses, significantly lower then the $A, B, C$ and D group in the cases of $N_{1}$ and $N_{2}$ for genera. $k$-dominance curves for combined replicates at each site produced an equivocal picture as many lines crossed, but Site D was clearly more diverse than the remainder (Fig. 15).

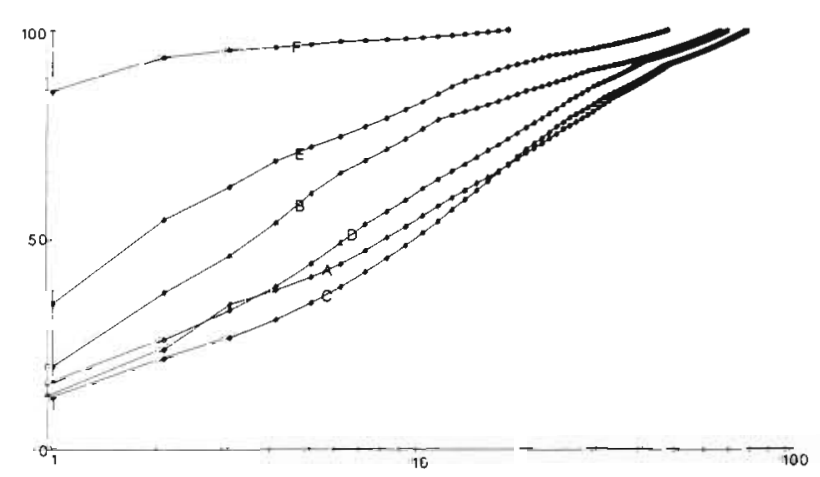

Fig. 13. Nematode species. $k$-dominance curves from combined data for 2 replicates at each of Sites A to F

\section{Higher meiofauna groups}

Total density of meiofauna was highest at the outermost site (A) and the innermost site (E). Sites B, C, D and F were similar to each other, with lower densities (Table 1). Although this pattern was determined largely by the dominant nematodes, it was also apparent in other taxonomic groups: Hydrozoa, Priapulida, Ostracoda and Copepoda also showed density maxima at A and $\mathrm{E}$. Kinorhyncha and Bivalvia had a single maximum at $\mathrm{A}$. Other taxa were more evenly represented at the various sites or were too rare to display any clear pattern. The

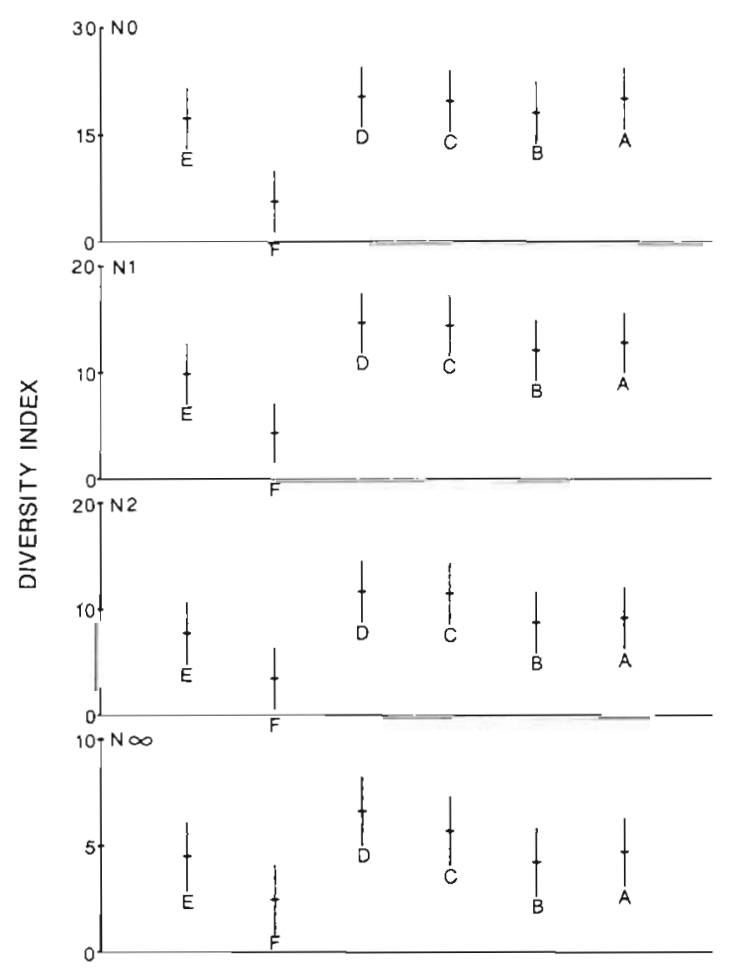

Fig. 14. Copepod species. Hill's diversity numbers $N_{0}, N_{1}, N_{2}$ and $N_{\infty}$ (means and comparison intervals, $n=3$ )

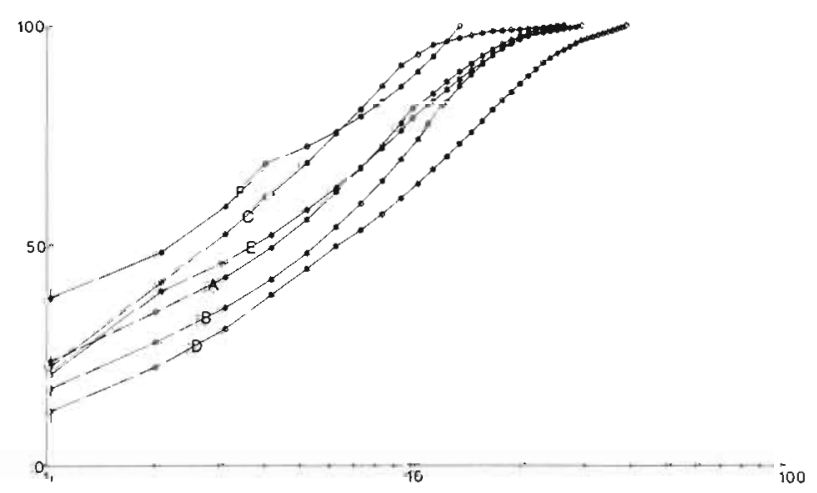

Fig. 15. Copepod species. $k$-dominance curves from combined data for 3 replicates 
density of the different groups was significantly different between sites, except for rare taxa and Oligochaeta.

Meiofauna group diversity was also significantly different for all diversity numbers (Table 2). Site $F$ had a lower $N_{0}$ (taxon richness) than all other sites, and a lower $N_{1}$ and $N_{2}$ than all other sites except E (Fig. 16). The nematode : copepod ratio at each site is given in Table 1. The general pattern of values is the inverse of many of the diversity measures given above, being highest at Site $F$ (59) and lowest at Sites A and D (14 and 15 respectively).

\section{DISCUSSION}

Results from the various types of multivariate analysis performed on the data differed only in small details, so that the choice largely depends on personal prefer-

Table 1. Mean abundance in 4 cores of the major groups of meiofauna at Sites $A$ to $F$, with calculations of density $\left(\mathrm{cm}^{-2}\right)$, individual dry wt $(\mu \mathrm{g})$ and total dry wt $\left(\mathrm{g} \mathrm{m}^{-2}\right)$, giving the nematode:copepod ratio both in terms of abundance and biomass. Numbers in individual replicates are given in Appendix 3, Table 7

\begin{tabular}{|c|c|c|c|c|c|c|}
\hline Group & A & B & C & $\mathrm{D}$ & E & F \\
\hline Hydrozoa & 32 & 9 & 14 & 10 & 17 & 0 \\
\hline Turbellaria & 89 & 27 & 35 & 14 & 31 & 3 \\
\hline Kinorhyncha & 120 & 1 & 0 & 0 & 0 & 0 \\
\hline Nematoda & 12427 & 3427 & 2485 & 1738 & 9358 & 516 \\
\hline Gastrotricha & 10 & 7 & 8 & 6 & 0 & 0 \\
\hline Priapulida & 31 & 3 & 3 & 1 & 32 & 0 \\
\hline Polychaeta & 93 & 99 & 166 & 132 & 70 & 4 \\
\hline Oligochaeta & 9 & 15 & 33 & 9 & 8 & 26 \\
\hline Bivalvia & 22 & 2 & 2 & 0 & 2 & 0 \\
\hline Ostracoda & 69 & 1 & 1 & 1 & 22 & 0 \\
\hline Copepoda & 893 & 108 & 132 & 118 & 330 & 9 \\
\hline Nauplii & 348 & 68 & 49 & 77 & 82 & 1 \\
\hline Amphipoda & 0 & 0 & 0 & 0 & 0 & 0 \\
\hline Tanaidacea & 0 & 4 & 17 & 1 & 0 & 0 \\
\hline Isopoda & 1 & 0 & 1 & 0 & 0 & 0 \\
\hline Cumacea & 3 & 0 & 3 & 0 & 0 & 0 \\
\hline Acari & 3 & 1 & 0 & 0 & 1 & 0 \\
\hline Tardigrada & 0 & 0 & 0 & 0 & 0 & 0 \\
\hline Echinodermata & 3 & 0 & 0 & 0 & 1 & 0 \\
\hline Total & 14154 & 3772 & 2949 & 2107 & 9953 & 559 \\
\hline \multicolumn{7}{|l|}{ Nematoda } \\
\hline Density & 470 & 130 & 94 & 66 & 354 & 20 \\
\hline Ind. wt & 0.83 & 1.30 & 0.59 & 1.50 & 0.68 & 0.90 \\
\hline Total wt & 3.90 & 1.69 & 0.55 & 0.99 & 2.41 & 0.18 \\
\hline \multicolumn{7}{|l|}{ Copepoda } \\
\hline Density & 33.8 & 4.1 & 5.0 & 4.5 & 12.5 & 0.3 \\
\hline Ind. wt & 2.14 & 16.39 & 6.49 & 3.03 & 2.43 & 7.49 \\
\hline Tota] wt & 0.72 & 0.67 & 0.32 & 0.14 & 0.30 & 0.03 \\
\hline \multicolumn{7}{|l|}{$\mathrm{N}: \mathrm{C}$ ratio } \\
\hline Density & 14 & 32 & 19 & 15 & 28 & 59 \\
\hline Biomass & 5.4 & 2.5 & 1.7 & 7.1 & 8.0 & 6.0 \\
\hline
\end{tabular}

Table 2. Significance of ANOVA on diversity of meiofaunal groups from 4 replicates at the 6 sites

\begin{tabular}{ccccccccc} 
Diversity: & $N_{0}$ & $N_{1}$ & $N_{2}$ & $N_{10}$ & $N_{10}^{\prime}$ & $N_{21}$ & $N_{21}^{\prime}$ \\
\hline$\cdots$ & $\cdot$ & $n s$ & $\cdots$ & $\cdots$ & $\cdots$ & $\cdot$ \\
& $\cdots<0.05$, & $\cdots$ & $p<0.01$, & $\cdots$ & $p<0.001$, ns: not significant
\end{tabular}
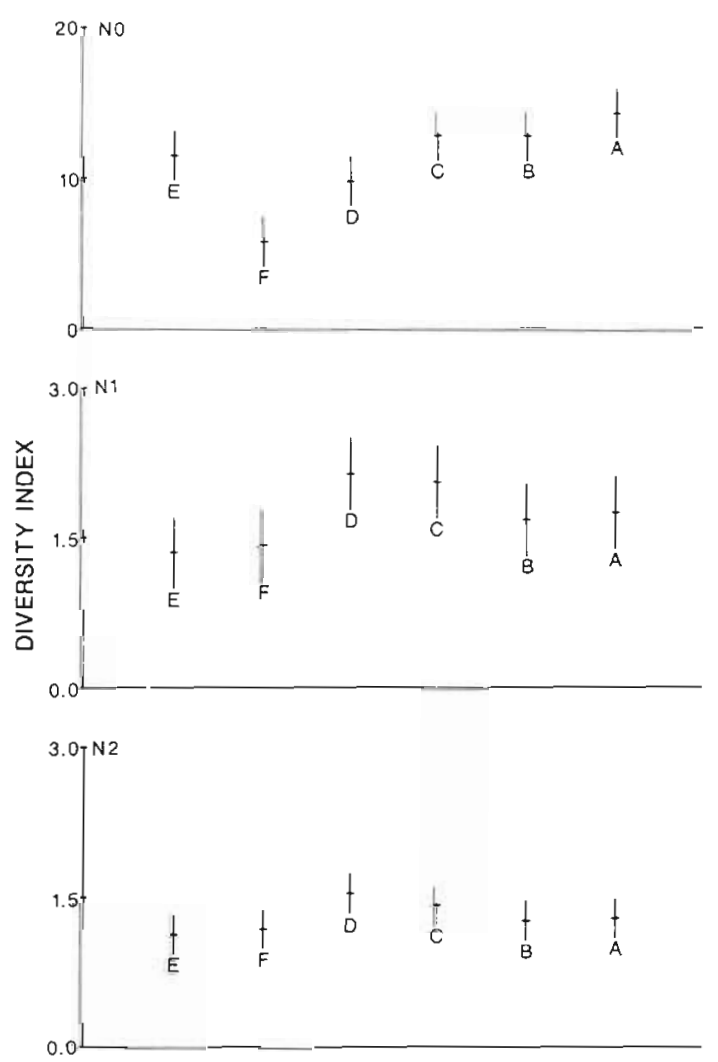

Fig. 16. Meiofauna major groups. Hill's diversity numbers (means and comparison intervals, $n=4$ )

ence, availability of programs or validity in terms of statistical assumptions (see Clarke \& Green 1988).

In their relative ability to discriminate between sites in the multivariate analyses, copepods were better than nematodes at the species level. However, nematodes were more robust to taxonomic aggregation than copepods. For nematodes, appreciable loss of information only occurred at the level of sub-orders and above whereas for copepods this occurred at the family level. The use in pollution-monitoring of the nematode and copepod components of the meiofauna at taxonomic levels higher than that of species is clearly viable, reducing the time spent in sorting and identification by up to $90 \%$. It is possible here to give some general guidelines with regard to appropriate taxonomic levels.

Analyses to the species level for both nematodes and copepods can realistically only be achieved by experi- 
enced specialists. Nematodes are identified from whole specimens (i.e. dissection is not required). It is now relatively simple, on a worldwide basis, to ascribe specimens to a genus using the pictorial key of Platt \& Warwick (1983). Workers with no previous experience and a small amount of instruction have found this possible, and the key is now used successfully in the tropics and Southern Hemisphere as well as in Northern Europe. Identification directly to generic level is in some respects simpler than ascribing specimens to families, and we would recommend working at this level in all relatively shallow water $(<200 \mathrm{~m})$ situations. Species determination of copepods requires dissection of the appendages, including mouthparts, which is a very daunting prospect for the non-specialist. Identification to generic level also requires dissection in many cases, but family determination can be done after a few hours practice, even under the binocular microscope. Working at the family level is therefore the most practical proposition for non-specialists.

Enumeration of the total meiofauna at the level of major taxa (e.g. nematodes, copepods) produced a moderate degree of discrimination between sites. If the so called 'temporary meiofauna' (larvae of macrofauna) are included, as we have done here, the picture is likely to be confounded by localised heavy spatfalls of planktonic larvae which may be only an ephemeral feature of the benthic community. Confining such analyses to taxa known to be exclusively meiofaunal might improve the picture, but we have not attempted this in the present study.

Pollution-studies using meiofauna are generally hampered by the lack of appropriate univariate measures of community stress. The concept of indicator species or higher taxa is poorly developed, although a few copepod and nematode taxa are known to be associated with organic enrichment of a fairly gross nature, for example the copepod Bulbamphiascus imus and large oncholaimid nematodes of several species. Copepods have been assumed to be more sensitive to pollution effects than nematodes (Raffaelli \& Mason 1981) and at Site $F$ were very reduced in numbers, with a consequently high nematode:copepod ratio. However, this latter response is not predictable in sublittoral sediments, where nutrient enrichment may have the reverse effect of increasing copepod numbers relative to nematodes (Vidakovic 1983, Gee et al. 1985, Moore \& Pearson 1986), particularly where dissolved oxygen is not depleted appreciably in the overlying water.

For reasons we have outlined in the Introduction to this paper, the application of ratios such as $B / A$ (the size ratio) or plotting $\mathrm{ABC}$ curves, as Gray et al. (1988) have done for the macrofauna, is unjustified. The analysis of trophic groups offers some promise, since in this study we have shown that the 4 trophic categories of nematodes discriminate rather well between sites in multivariate analyses. At present, not enough empirical evidence is available to establish predictable changes in trophic organization in response to pollution. However, there is some evidence that non-selective deposit feeding nematodes (Feeding group 1B) become dominant in polluted waters, and Vincx (in Heip et al. 1985) proposed the use of a trophic index based on the relative abundance of feeding types of nematodes. She showed a linear relation between this index and heavy metal levels in sediments of the North Sea off the Belgian coast.

At present, therefore, much reliance has to be placed on diversity measures, which can only be applied on a comparative basis, and for the meiofauna these are strongly affected by 'nuisance variables', particularly sediment granulometry. On the basis of such calculations, only Site F was clearly separated from the others in terms of lower diversity, which was evident at all taxonomic levels. For several measures, the innermost site (E) also had lower diversity values, mainly for $N_{1}$ and $N_{2}$ which are based on relative abundance. This may indicate a shift towards dominance of the more tolerant groups without causing the complete disappearance of other species or higher taxa.

The marked separation of Site $F$ in the multivariate analyses, and its low meiofaunal diversity relative to the other sites, correlates with much higher PAH and cadmium levels. This site is of intermediate water depth, so that its distinctive characteristics do not relate to naturally occurring depth-related environmental variables such as seasonal anoxia, as did the apparently stressed macrofauna communities of the region (Gray et al. 1988). Unfortunately, no granulometric analysis of the sediment is available for this site, but for the purposes of meiofauna extraction the sediment passed easily and completely through a $63 \mu \mathrm{m}$ sieve, thus comprising fine silt similar to that of Sites A, C, D and $E$. There is thus strong correlative evidence that the meiofauna at Site $F$ is affected by pollution.

In many of the multivariate analyses, the remaining Sites A to E are grouped in the same way as comparable macrofaunal analyses, as indicated in the overview of the community studies by Warwick (1988). Therefore, as for the macrofauna, naturally occurring depth-related factors rather than pollution are implicated (Gray et al. 1988). However, unlike the macrofauna, the meiofauna at the deeper sites $B, C$ and D do not show any signs of being more stressed than at the other sites, having comparatively high diversity. If seasonal anoxia is indeed the cause of stress in the macrofaunal communities at these sites (Gray et al 1988), it may be that meiofaunal communities are less sensitive to this, or because of rapid generation times can recover from it seasonally. Alternatively, it may be 
that as yet we have inadequate means of determining stress in the meiofauna at the community level: diversity proved to be a poor measure for the macrofauna also.

Acknowledgements. We are grateful to Chris George and Odd-Arne Follum who collected the samples, to Bob Clarke for statistical consultation and to Andrea Gigg for figure preparation

\section{LITERATURE CITED}

Alatalo (1981). Problems in the measurement of evenness in ecology. Oikos 37: 199-205

Clarke, K. R., Green. R. H. (1988), Statistical design and analysis for a 'biological effects' study. Mar. Ecol. Prog Ser. 46: $213-226$

Follum, O. A., Moe, K. A. (1988). The GEEP Workshop: field sampling. Mar. Ecol. Prog. Ser. 46: $7-12$

Gee, J. M., Warwick, R. M., Schanning, M., Berge, J. A., Ambrose Jr, W. G. (1985). Effects of organic enrichment on meiofaunal abundance and community structure in subLittoral soft sediments. J. exp. mar. Biol. Ecol. 91: 247-262

Gray, J. S., Aschan, M., Carr, M. R., Clarke, K. R., Green, R. H., Pearson, T. H., Rosenberg R., Warwick, R. M. (1988). Analysis of community attributes of the benthic macrofauna of Frierfjord/Langesundfjord, and in a mesocosm experiment. Mar. Ecol. Prog. Ser. 46: 151-165

Heip, C. (1974). A new index measuring evenness. J. mar. biol. Ass. U. K. $54: 559-563$

Heip, C. (1980). Meiobenthos as a tool in the assessment of marine environmental quality. Rapp. P.-v. Réun. Cons. int. Explor. Mer 179: 182-- 187

Heip, C., Herman, P. M. J. (1985). The stability of a benthic copepod community. In: Gibbs, P. E. (ed.) Proceedings 19th European Marine Biology Symposium. Cambridge University Press, Cambridge, p. 255-263

Heip, C., Vincx, M., Vranken, G. (1985). The ecology of marine nematodes. Oceanogr. mar Biol. A. Rev. 23. $399-489$

Herman, P. M. J., Heip, C. (1986). The predictability of biolog ical populations and communities: an example from the meiobenthos. Hydrobiologia 142: 281-290

Hill, M. O. (1973). Diversity and evenness: a unifying notation and its consequences. Ecology 54: $427-432$
Lambshead, P. J. D., Platt, H. M., Shaw, K. M. (1983). The detection of differences among assemblages of marine benthic species based on an assessment of dominance and diversity. J. nat. Hist. 17: 859-874

McIntyre, A D. (1969). Ecology of marine meiobenthos. Biol. Rev. 44: 245-290

McIntyre, A. D., Warwick, R. M. (1984). Meiofauna techniques. In: Holme, N. A., McIntyre, A. D. (eds.) Methods for the study of marine benthos. Blackwell, Oxford, p. $217-244$

Moore, C. G., Pearson, T. H. (1986). Response of a marine benthic copepod assemblage to organic enrichment. Proc. 2nd. Int. Conf. Cop., Syllogeus ser. No, 58, National Museums of Canada, p. 369-373

Platt, H. M., Warwick, R. M. (1983). Free-living marine nematodes. Part 1. British enoplids. Cambridge University Press, Cambridge

Raffaelli, D. G., Mason, C. F. (1981). Pollution monitoring with meiofauna, using the ratio of nematodes to copepods. Mar. Pollut. Bull. 12: 158-163

Renyi, A. (1961). On measures of entropy and information. In Neyman, J. (ed.) Proc. 4th Berkeley symposium on mathematical statistics and probability, Berkeley, $p$. $547-561$

Schwinghamer, P. (1981). Characteristic size distributions of integral benthic communities. Can. J. Fish. aquat. Sci. 38: $1255-1263$

Sokal, R. R., Rohlf, F. J. (1981). Biometry, W. H. Freeman \& Co., San Francisco

Vidakovic, J. (1983). The influence of raw domestic sewage on density and distribution of meiofauna. Mar. Pollut. Bull. $14: 84-88$

Warwick, R. M. (1980). Population dynamics and secondary production of benthos. In: Tenore, K. R., Coull, B. C. (eds.) Marine benthic dynamics. Univ. South Carolina Press, Columbia, p. 1-24

Warwick, R. M. (1984). Species size distributions in marine benthic communities. Oecologia (Berl.) 61: 32-41

Warwick, R. M. (1988). Effects on community structure of a pollutant gradient - summary. Mar. Ecol. Prog. Ser. 46: $207-211$

Warwick, R. M., Collins, N. R., Gee, J. M., George, C. L. (1986). Species size distributions of benthic and pelagic Metazoa: evidence for interaction? Mar. Ecol. Prog. Ser. $34: 63-68$

Wieser, W. (1953). Die Beziehung zwischen Mundhöhlengestalt, Enährungsweise und Vorkommen bei freilebenden marinen Nematoden. Ark. Zool. Ser. 2, 4: 439-484 